\title{
Preface to Update on Parasellar Tumours: ENEA Workshop, Athens, December 6-7, 2019
}

The great majority of pituitary "tumours" arise from the adenohypophyseal cells, whether one refers to them as pituitary adenomas or PitNETs (pituitary Neuroendocrine Tumours). However, a significant minority of masses in and around the sella, the parasellar lesions, are seen by many specialists in this area and have a diverse set of presentations, imaging, and pathology. It is important to all of those dealing with pituitary lesions to be aware of these different types of inflammatory and neoplastic masses, as their treatment differs quite markedly from that of the typical pituitary adenoma. Very often their existence is suspected by their mode of presentation, such as severe headache and invasive characteristics in a patient with evidence of a metastatic cancer, or with diabetes insipidus, a disorder rarely if ever associated with a pituitary tumour arising from adenohypophyseal cells. Sometimes only the unexpected histopathology leads to a correct diagnosis and thus determines the optimal treatment. Whatever the case, it has until now been difficult to access information on the great variety of these lesions in a single place.

To that end, Prof. Gregory Kaltsas, Dr. Krystallenia Alexandraki, and colleagues organized a workshop specifically on parasellar lesions in Athens, Greece, in December 2019, under the aegis of the ENEA headed by Prof. Thierry Brue. Experts from many different countries and disciplines were invited to contribute to this meeting, and it was decided to make available the core substance of many of these lectures in a more long-lasting form in this special issue of Neuroendocrinology. We are very grateful to all of the contributors to this volume for their time and effort in attending the meeting and helping with this supplement.

Greg Kaltsas, Thierry Brue, and all of the various authors hope that you will find these articles of use and benefit in treating our patients, to their ultimate benefit.

\section{Ashley Grossman}

London and Oxford, May 2020 